\title{
A systematic review evaluating the impact of task shifting on access to antiretroviral therapy in sub-Saharan Africa
}

\author{
*Emdin CA, Millson P \\ Dalla Lana School of Public Health, University of Toronto, 155 College Street, Health Science Building, \\ 6th floor, Toronto, ON M5T 3M7
}

\begin{abstract}
Background: Task shifting, defined for this review as the shifting of ART initiation and management from physicians to nurses, has been proposed as a possible method to increase access to HIV treatment in Sub-Saharan Africa.

Objective: To critically evaluate the literature on task shifting, determining if there is evidence to support this view.

Methods: A systematic search of the literature was undertaken, with both peer reviewed publications and conference abstracts presenting original data eligible for inclusion. Studies were evaluated according to methodology and discussion of confounding factors.

Results: We identified 25 articles which evaluated the effect of task shifting on access to ART. The evidence was mixed. Although there is a significant body of field reports indicating that task shifting increases access, these studies were of low methodological quality. The only randomized controlled trial included in this review did not find that task shifting increased in access.

Conclusion: Task shifting appears to be most effective at increasing access when combined with other interventions and financial support. There is a need for more research into the effects of task shifting policies, especially randomized controlled trials and high quality cohort studies.

Key words:task shifting, antiretroviral therapy, nurse provided treatment, substitution of physicians, access to HIV treatment African Health Sciences 2012; 12(3): 318 - 324 http://dx.doi.org/10.4314/ahs.v12i3.11
\end{abstract}

\section{Introduction}

While the spread of HIV / AIDS is a global epidemic, Sub-Saharan Africa is the region most highly affected. ${ }^{1}$ One factor limiting the scale up of antiretroviral therapy and other HIV services is the severe health care worker shortage facing Africa. ${ }^{2}$ Task shifting, the gradual transfer of ART management and initiation from doctors to nurses and other non-physician clinicians, has been proposed to address this problem. Task shifting has been well studied in both high and low resource settings and good patient outcomes have been consistently reported. A 2010 systematic review of task shifting with regard to antiretroviral therapy concluded that nurse managed ART offered high quality care equivalent to physician managed care. ${ }^{2}$ Because of the existing strong evidence and consensus in the literature that task shifting has good outcomes, this

\begin{tabular}{l}
\hline *Correspondence author: \\
Connor Emdin \\
School of Public Health \\
University of Toronto \\
155 College Street, Health Science Building \\
6th floor, Toronto \\
ON M5T 3M7 \\
Telephone: 1-416-836-6821 \\
Email: connor.emdin@utoronto.ca \\
\hline 18
\end{tabular}

systematic review will not focus on evaluating patient outcomes. Instead, this review will evaluate whether task shifting of ART initiation and management from physicians to nurses increases access to antiretroviral therapy, the primary purpose cited for the implementation of task shifting policies.

\section{Methods}

To identify articles for this review, three search themes were combined with the boolean operator "and". The first search theme was centered around task shifting, which was combined with the theme of HIV and the theme of antiretrovirals. Multiple synonyms for each theme were used. The following databases were searched until February 2012: PubMed, South African Health Research Index, Cochrane Central Register of Controlled Trials, Popline, CINAHL, EMBASE, AIDSLine, Social Science Citation Index and Arts \& Humanities Citation Index. The abstract databases of the International AIDS Society Conferences, the Conferences on Retroviruses and Opportunistic Infections and the conferences of the International Society of Sexually Transmitted Disease Research were searched. Bibliographies of relevant papers were also reviewed and a grey literature search was 
conducted. Literature had to be applicable to SubSaharan Africa or low resource settings and had to measure access to antiretroviral therapy. Patient enrollment was used as the primary indicator of access while wait times, workforce and loss to follow up were evaluated as secondary measures of access. Articles identified as relevant to access to ART were evaluated for quality according to methodology and discussion of confounding factors.

\section{Results}

\section{Search Process}

Following search and screening, twenty-five studies were chosen for inclusion in the review. (Figure 1) Due to the heterogenous nature of the results, a quantitative meta-analysis would have been inappropriate. Instead, a qualitative synthesis was used to evaluate the existing evidence.

Table 1: Characteristics of studies considered in this systematic review

\begin{tabular}{|c|c|c|c|c|c|}
\hline Locatio & & $\begin{array}{l}\text { Design/ } \\
\text { Size }\end{array}$ & Measurement & t Outcomes & Methodological limitations \\
\hline Assefa et al. $2011^{9}$ & Ethiopia & $\begin{array}{l}\text { Cohort/ } \\
184978\end{array}$ & $\begin{array}{l}\text { Loss to follow } \\
\text { up }\end{array}$ & $\begin{array}{l}\text { Nurse managed care reduced } \\
\text { loss to follow up but there } \\
\text { was a high cost for training } \\
\text { and mentorship }\end{array}$ & $\begin{array}{l}\text { Facilities were not selected } \\
\text { randomly, loss to follow up } \\
\text { was not investigated }\end{array}$ \\
\hline Bedelu et al. $2007^{16}$ & $\begin{array}{l}\text { South } \\
\text { Africa }\end{array}$ & $\begin{array}{l}\text { Cohort/ } \\
1025\end{array}$ & Enrollment & $\begin{array}{l}\text { Task shifting policies doubled } \\
\text { enrollment }\end{array}$ & $\begin{array}{l}\text { Many other program } \\
\text { improvements used }\end{array}$ \\
\hline $\begin{array}{l}\text { Bemelmans et } \\
\text { al. } 2010^{15}\end{array}$ & Malawi & $\begin{array}{l}\text { Cohort/ } \\
23361\end{array}$ & Enrollment & $\begin{array}{l}\text { Task shifting double } \\
\text { enrollment to } 23361 \text { patients, } \\
\text { allowed for universal access with } \\
\text { in Thylolo, Malawi }\end{array}$ & $\begin{array}{l}\text { Many other program } \\
\text { improvements used }\end{array}$ \\
\hline $\begin{array}{l}\text { Brennan et al. } \\
2011^{11}\end{array}$ & $\begin{array}{l}\text { South } \\
\text { Africa }\end{array}$ & $\begin{array}{l}\text { Cohort/ } \\
2772\end{array}$ & $\begin{array}{l}\text { Loss to follow } \\
\text { up }\end{array}$ & $\begin{array}{l}\text { Down referral to nurse } \\
\text { managed treatment resulted } \\
\text { in reduced loss to follow up } \\
\text { rates }\end{array}$ & Single clinic examined \\
\hline $\begin{array}{l}\text { Cohen et al. } \\
2009^{19}\end{array}$ & Lesotho & $\begin{array}{l}\text { Cohort/ } \\
13243\end{array}$ & Enrollment & $\begin{array}{l}\text { Annual enrollment doubled } \\
\text { from } 2006 \text { to } 2008 \text { with no } \\
\text { increase in human resources } \\
\text { through task shifting }\end{array}$ & $\begin{array}{l}\text { Other improvements } \\
\text { including early initiation of } \\
\text { ART, external funding }\end{array}$ \\
\hline $\begin{array}{l}\text { Fairall et al. } \\
2012^{27}\end{array}$ & $\begin{array}{l}\text { South } \\
\text { Africa }\end{array}$ & $\begin{array}{l}\text { RCT/ } \\
15571\end{array}$ & Enrollment & $\begin{array}{l}\text { No significant reduction } \\
\text { in waiting list mortality } \\
\text { for task shifting clinics (HR } \\
=0.92 \text { for death, } \mathrm{p}=0.53 \text { ) }\end{array}$ & $\begin{array}{l}\text { Only } 26 \% \text { of patients in the } \\
\text { nurse cohort were initiated by a } \\
\text { nurse }\end{array}$ \\
\hline $\begin{array}{l}\text { Fredlund et al. } \\
2007^{22}\end{array}$ & $\begin{array}{l}\text { South } \\
\text { Africa }\end{array}$ & $\begin{array}{l}\text { Cohort/ } \\
1311\end{array}$ & Enrollment & $\begin{array}{l}\text { Decentralization to a primary } \\
\text { clinic improved access, } \\
\text { nurse initiation of ART prev- } \\
\text { ented waiting lists }\end{array}$ & $\begin{array}{l}\text { Decentralization and } \\
\text { community support were used }\end{array}$ \\
\hline $\begin{array}{l}\text { Hartman et al. } \\
2011^{13}\end{array}$ & Ethiopia & $\begin{array}{l}\text { Cohort/ } \\
80000\end{array}$ & Enrollment & $\begin{array}{l}\text { Nurse managed ART services } \\
\text { provided to } 80000 \text { people, } \\
\text { loss to follow up rate is } 9 \% \\
\text { compared to } 20 \% \text { nationally }\end{array}$ & $\begin{array}{l}\text { Not peer reviewed, no } \\
\text { comparison group, significant } \\
\text { external funding } \\
\text { Not peer reviewed, no }\end{array}$ \\
\hline $\begin{array}{l}\text { Hulela et al. } \\
2008^{24}\end{array}$ & Botswana & $\begin{array}{l}\text { Cohort/ } \\
20000\end{array}$ & Enrollment & $\begin{array}{l}\text { Task shifting increased access to } \\
\text { ART, allowed } 20000 \text { patients } \\
\text { to receive treatment at rural } \\
\text { clinics }\end{array}$ & $\begin{array}{l}\text { o comparison group or } \\
\text { discussion of confounding } \\
\text { factors }\end{array}$ \\
\hline $\begin{array}{l}\text { Humphreys et } \\
\text { al. } 2010^{7}\end{array}$ & Swaziland & $\begin{array}{l}\text { Cohort/ } \\
474\end{array}$ & $\begin{array}{l}\text { Loss to follow } \\
\text { up }\end{array}$ & $\begin{array}{l}\text { Nurse managed ART resulted } \\
\text { in increased clinic attendance anc } \\
\text { retention }\end{array}$ & $\begin{array}{l}\text { Decentralization also present } \\
\text { nd }\end{array}$ \\
\hline $\begin{array}{l}\text { Ivers et al. } \\
2011^{21}\end{array}$ & Haiti & $\begin{array}{l}\text { Survey/ } \\
11114\end{array}$ & Enrollment & $\begin{array}{l}11114 \text { people were enrolled in } \\
\text { ART therapy over five years } \\
\text { using a task shifting model; } \\
\text { Currently no waiting lists for } \\
\text { treatment; Low rates of loss to } \\
\text { follow up }\end{array}$ & $\begin{array}{l}\text { External funding, } \\
\text { observational study }\end{array}$ \\
\hline
\end{tabular}




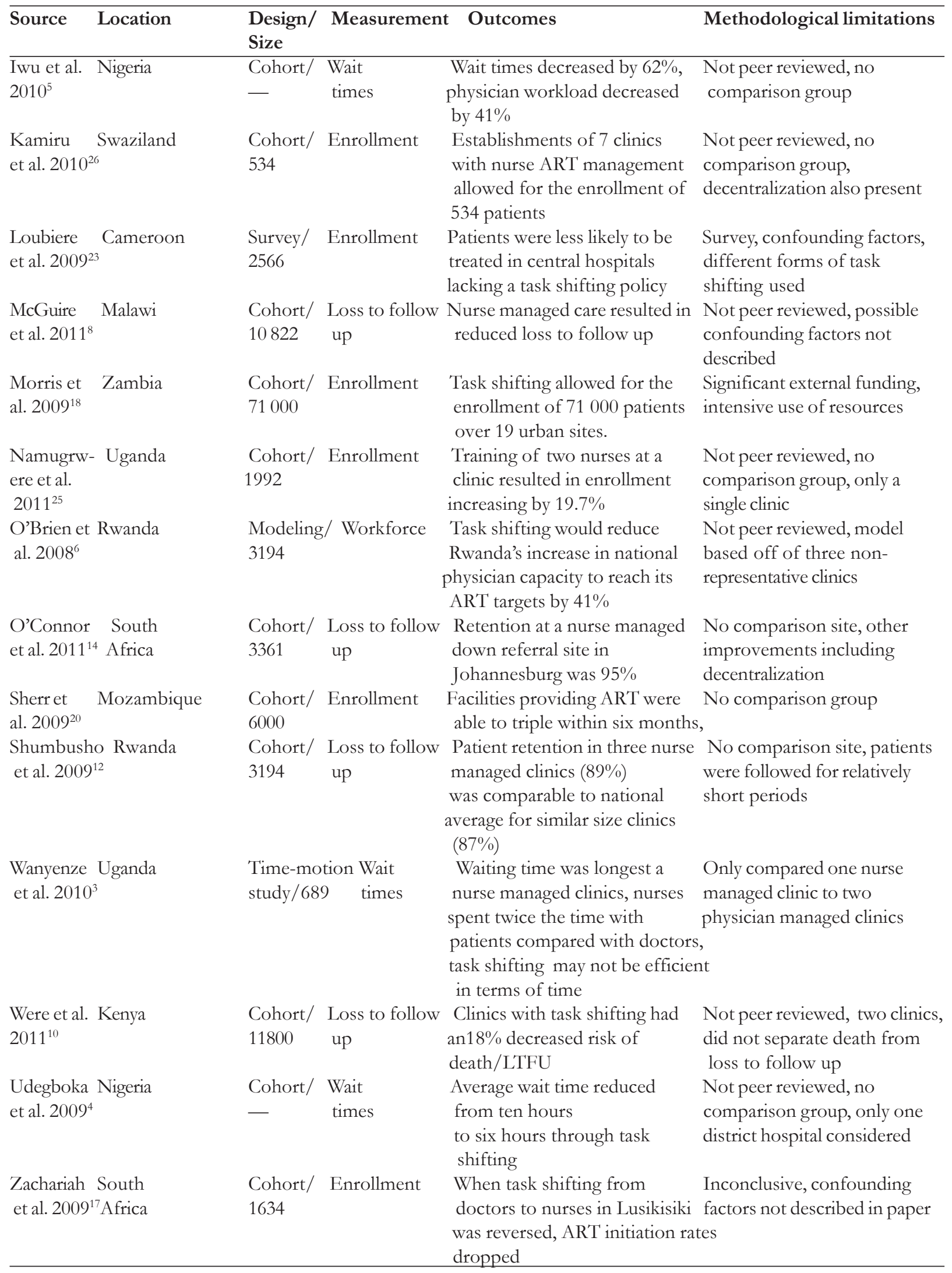


Figure 1: Flow chart of serach and screening process

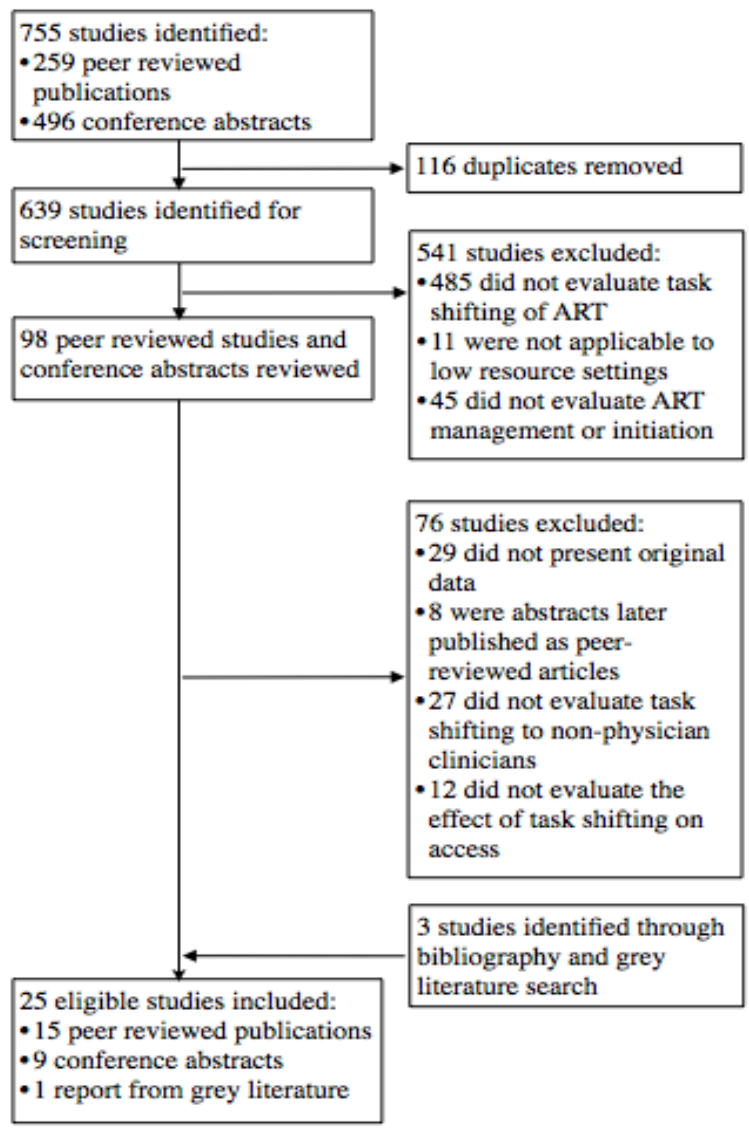

Wait times and Workforce

There have been many studies examining the effects of task shifting on secondary measures of access including wait times, workforce hours and retention in care (loss to follow up). The evidence is mixed. Wanyenze et al. ${ }^{3}$ found that wait times in nurse managed clinics were significantly longer than those in physician managed clinics while two contradictory studies found that task shifting resulted in a decrease in mean wait time. ${ }^{4,5}$ O'Brien et al. measured the effect that task shifting has on physicians' workload in Rwanda on the assumption that a reduced workload would allow physicians to redirect their time to enrolling patients. ${ }^{6}$ They calculated that without task-shifting policies, Rwanda will need to increase their physician workforce by $52 \%$ to hit ART enrollment targets. With task shifting policies, this increase is reduced to $11 \%$.

\section{Loss to Follow up}

There is a significant body of evidence indicating that nurse managed care increases retention and reduces loss to follow up. Cohort studies from Swaziland ${ }^{7}$, Malawi ${ }^{8}$, Ethiopia, ${ }^{9}$ Kenya $^{10}$ and South Africa ${ }^{11}$ all found that clinics with task-shifting policies had reduced loss to follow up rates compared to similar clinics lacking task-shifting policies. Cohort studies in Rwanda ${ }^{12}$, Ethiopia ${ }^{13}$ and South Africa ${ }^{14}$ found that the retention rates at nurse managed clinics, $89 \%, 91 \%$ and $95 \%$ respectively, were above the national average in each country.

\section{Patient Enrollment}

There are a number of field reports suggesting that task shifting can be used to increase enrollment in antiretroviral therapy on a district and nation wide scale. In Thyolo, Malawi, task shifting from doctors to non-physician clinicians (primarily nurses) doubled ART initiation and allowed for universal access by 2009. ${ }^{15}$ In Lusikisiki, South Africa, ART initiation by nurses within rural clinics allowed for the doubling of initiation of patients. ${ }^{16}$ When this form of task shifting was reversed in 2006, with ART initiation restricted to physicians, ART initiation rates declined. ${ }^{17}$ Task shifting policies in Zambia ${ }^{18}$ Lesotho $^{19}$ and Mozambique ${ }^{20}$ were all reported to allow for a dramatic increase in patient enrollment. Studies in Haiti $^{21}$, South Africa ${ }^{22}$ and Cameroon ${ }^{23}$ all found that task shifting policies reduced waiting lists for HIV treatment. Field reports from Botswana ${ }^{24}$, Uganada ${ }^{25}$ and Swaziland ${ }^{26}$ observed task shifting policies increased the enrollment of patients at primary clinics.

The only randomized controlled trial evaluating task shifting's effect on access recently reported initial data. The Streamlining Tasks and Roles to Expand Treatment and Care for HIV (STRETCH) trial randomly assigned 16 clinics in the Free State Province of South Africa to put in place policies of nurse managed and initiated HIV treatment and compared them to fifteen clinics which kept conventional physician care. ${ }^{27}$ This trial occurred under the normal constraints of a public health system in a middle income country; training for nurse initiated ART was hindered by the high turnover rate and there was also difficulty in maintaining adequate ART supplies. Contrary to expectations, nurse initiation of antiretroviral therapy did not reduce waiting list mortality, with a hazard ratio of 0.92 for death $(p=0.532)$ between nurse initiated and physician initiated clinics. However, this effect varied with patients' CD4 levels. The waiting list mortality for patients with CD4 $<200$ was equivalent for nurse and physician initiated clinics $(\mathrm{HR}=1.0)$ while the 
waiting list mortality for patients with CD4 levels between 200 and 350 was reduced, although not significantly, at nurse initiated clinics ( $\mathrm{HR}=0.73, \mathrm{p}$ $=0.052$ ). There is an apparent contradiction between the evidence from this randomized controlled trial and the body of field reports, which will be elaborated on further in the discussion.

\section{Discussion}

The reported ability of task shifting to improve access to ART varies according to the measurement of access and the quality of the study. There is strong and consistent evidence that task shifting reduces loss to follow up and increases retention in care from studies in multiple countries in sub-saharan Africa. This has been attributed to the decentralization associated with task shifting. ${ }^{16}$ Providing treatment closer to patients' homes removes barriers associated with travel such as costs and taking time off work. ${ }^{16}$ As clinicians tend to be concentrated in urban areas, the availability of physicians to prescribe ART at peripheral sites can be the limiting factor for treatment. ${ }^{16}$ Task shifting can thus strengthen the positive effects of decentralization by increasing the availability of clinicians at peripheral sites.

Field reports from multiple countries including Swaziland, Uganda, Rwanda, South Africa and Lesotho have all found that task shifting increases patient enrollment in ART. However, many of these studies suffer from significant methodological flaws such as a lack of comparison group. Further increasing the difficulty in interpreting these reports is the presence of confounding factors. Task shifting to nonphysician clinicians was typically only one of several interventions reported in these studies. Many included separate task shifting to lay workers ${ }^{15,16}$, the use of first line tenofovir ${ }^{19}$ and community support ${ }^{22}$. These interventions have also benefited from substantial external funding from NGOs and may not reflect what is feasible within the constraints of a public health system ${ }^{28}$. The STRETCH randomized controlled trial, on the other hand, was conducted within all of the usual constraints of an underfunded public health system. Initial results, however, have indicated that it did not improve access to ART, as measured by a statistically significant decrease in waiting list mortaliyt ${ }^{27}$. A possible explanation for this apparent lack of effect is the difficulty in training nurses for their new roles and the high staff turnover throughout the trial. ${ }^{27}$ Only $26 \%$ of patients in the nurse initiated arm of the trial were actually initiated by nurses, suggesting that the STRETCH intervention was not fully implemented in the nurse initiating clinics ${ }^{27}$. The lack of a corresponding shifting of tasks from nurses to lay workers with the introduction of nurse initiated ART may also have overburdened nurses, inhibiting access to ART. In addition, the doctor initiated arm of the trial was able to dramatically increase prescribing rates during the trial. ${ }^{27}$

With the lack of high quality evidence that the STRETCH trial would have provided, it is difficult to validate the current expansion of nurse initiated care that is occurring in South Africa, Lesotho and other countries in Sub-Saharan Africa. However, the discrepancy between the results of the STRETCH trial and the field reports suggest external factors that may influence the efficacy of task shifting policies. The field reports suggest that improved access to ART came through a combination of task shifting policies with other interventions such as decentralization, task shifting to lay workers and community support, interventions lacking in the STRETCH trial. This suggests that task shifting should not be considered in isolation but rather as a part of the solution to the severe health care worker shortage in Africa. Task shifting to lay workers, for example, may be critical to ensuring that nurses' workloads stay manageable with the additional responsibilities of providing HIV treatment. ${ }^{16}$ Without the further inclusion of lay workers, increased access to treatment may be limited by the availability of nurses ${ }^{16}$. Similarly, measures such as increased pay for health care workers to improve retention, investment in long term training and increases in funding may increase the likelihood that task shifting policies can improve access ${ }^{29}$. Additionally, there is a significant body of evidence demonstrating equivalent outcomes between nurse and physician initiated $\mathrm{ART}^{2}$ and there is evidence suggesting potential cost savings through the adoption of task shifting policies. ${ }^{2}$ In this view, task shifting policies should be considered as an effective method of providing ART but not an effective method of increasing access to ART unless combined with significant training, support and other interventions.

It is important to acknowledge the limitations of this review. Although this review focused on the task shifting of ART management and initiation, these two terms encompass a broad range of tasks including testing, prescription of medicine, dispensing medicine, detection of complications and referral. Studies which refer to the same form of task shifting 
may, in practice, implement highly dissimilar forms. ${ }^{2}$ While this hinders the comparison of studies, it may explain the variation in access seen in this review. Similarly, there can be substantial variation in the training and competencies of nurses or nonphysician clinicians between different countries and regions. Differing workloads prior to implementation of task shifting can also impact the ability of nurses to increase initiation rates, as previously mentioned.

There is substantial evidence that task shifting provides equivalent outcomes as traditional physician managed treatment ${ }^{2}$ and this review provides further support for task shifting policies when implemented with additional strengthening programs. However, there remains resistance among many health authorities to implementing task shifting policies. Professional groups, for example, have objected to what they view as an encroachment of their authority. ${ }^{17}$ If task shifting is to be adopted across Sub-Saharan Africa, it is critical that research be done to identify these barriers and methods of removal.

\section{Conclusion}

Although there is a large body of literature evaluating the effect of task shifting on access to antiretroviral therapy, much of it is hampered by poor methodology and the presence of confounding factors. A recent randomized controlled trial comparing clinics with nurse initiated ART against clinics with only physician initiated ART failed to find a statistically significant increase in access to ART. However, there is evidence that when combined with other interventions to strengthen the workforce and increase funding, task shifting can be effective at improving access. Therefore, task shifting policies should be considered by nations attempting to improve access but only as part of a broader set of efforts to improve HIV treatment. There is a need for more research into the effects of task shifting policies, especially randomized controlled trials and high quality cohort studies. However, trials comparing HIV treatment with and without task shifting policies may pose ethical issues that should be carefully considered prior to implementation. Studies comparing the efficacy of various combinations of task shifting policies would also be valuable and could help determine which support and training mechanisms are necessary to provide high quality care.

\section{Acknowledgements}

African Health Sciences Vol 12 No 3 September 2012
Connor A Emdin is the recipient of the Heaslip Scholarship from University of Toronto.

\section{Conflicts of Interest}

The authors have no conflicts of interest to report.

\section{References}

1. UNAIDS. Global Report on the AIDS Epidemic. 2010.

2. Callaghan M, Ford N, Schneider H. A systematic review of task- shifting for HIV treatment and care in Africa. Human Resources for Health 2010; 8: 83 .

3. Wanyenze RK, Wagner G, Alamo S, et al. Evaluation of the efficiency of patient flow at three HIV clinics in Uganda. AIDS Patient Care and STDs 2010; 24(7): 441-6

4. N Udegboka HM-J. Reduction of client waiting time through task shifting in Northern Nigeria. International AIDS Conference; Cape Town 2009

5. E Iwu IE, I Ezebuihe, O Caroline, E Umaru, A Gomwalk, M Moen, R Riel, J Johnson. Task shifting - a strategic response to human resource for health crisis: qualitative evaluation of hospital based HIV clinics in North central Nigeria. International AIDS Conference; Vienna 2010

6. Megan E O'Brien JC, Agnes Binagwaho, Fabienne Shumbusho, Jessica Price. Nurse delivery of HIV care: Modeling the impact of taskshifting on physician demand. Bill and Melinda Gates Foundation, 2008.

7. Humphreys CP, Wright J, Walley J, et al. Nurse led, primary care based antiretroviral treatment versus hospital care: a controlled prospective study in Swaziland. BMC Health Services Research. 2010; 10: 229

8. M McGuire GP, S Goossens, A Heinzelmann, O Chikwaza, E Szumilin, M Berthelot, M Pujades-Rodriguez. Task-shifting of HIV care and ART initiation: three year evaluation of a mixed-care provider model for ART delivery. International AIDS Conference; Rome 2011

9. Assefa Y, Kiflie A, Tekle B, Mariam DH, Laga M, Van Damme W. Effectiveness and acceptability of delivery of antiretroviral treatment in health centres by health officers and nurses in Ethiopia. Journal of Health Services Research \& Policy 2011; (1): 24-9

10. MC Were JG, S Macharia, C Shen, CT Yiannoutsos, WM Tierney. Achieving quarterly 
physician visits for HIV-patients through taskshifting to nurses: a comprehensive prospective evaluation in Sub-Saharan Africa. International AIDS Conference; Rome 2011

11. Brennan AT, Long L, Maskew M, et al. Outcomes of stable HIV-positive patients down-referred from a doctor-managed antiretroviral therapy clinic to a nurse-managed primary health clinic for monitoring and treatment. AIDS 2011; 25 (16): 2027-36

12. Shumbusho F, van Griensven J, Lowrance D, et al. Task shifting for scale-up of HIV care: evaluation of nurse-centered antiretroviral treatment at rural health centers in Rwanda. PLoS medicine. 2009;6(10):e1000163. Oct.

13. AF Hartman WC, E Konings, T Arega. National expansion of comprehensive HIV/AIDS services in Ethiopia: lessons learned from decentralizing HIV care and treatment to the community level in resource poor settings. International AIDS Conference; Rome 2011

14. O'Connor C, Osih R, Jaffer A. Loss to followup of stable antiretroviral therapy patients in a decentralized down-referral model of care in Johannesburg, South Africa.J Acquir Immune Defic Syndr 2011; 58 (4): 429-32

15. Bemelmans M, Van Den Akker T, Ford N, et al. Providing universal access to antiretroviral therapy in Thyolo, Malawi through task shifting and decentralization of HIV/AIDS care. Tropical Medicine \& International Health 2010; 15 (12): 1413-20

16. Bedelu M, Ford N, Hilderbrand K, Reuter H. Implementing antiretroviral therapy in rural communities: the Lusikisiki model of decentralized HIV/AIDS care. The Journal of Infectious Diseases 2007; 196 Suppl 3: S464-8

17. Zachariah R, Ford N, Philips M, et al. Task shifting in HIV/AIDS: opportunities, challenges and proposed actions for sub-Saharan Africa. Transactions of the Royal Society of Tropical Medicine and Hygiene 2009; 103 (6): 549-58

18. Morris MB, Chapula BT, Chi BH, et al. Use of task-shifting to rapidly scale-up HIV treatment services: experiences from Lusaka, Zambia. BMC Health Services Research 2009; 9: 5

19. Cohen R, Lynch S, Bygrave H, et al. Antiretroviral treatment outcomes from a nurse-driven, community-supported HIV/AIDS treatment programme in rural Lesotho: observational cohort assessment at two years. Journal of the International AIDS Society 2009; 12: 23

20. Sherr K, Pfeiffer J, Mussa A, et al. The role of nonphysician clinicians in the rapid expansion of HIV care in Mozambique. J Acquir Immune Defic Syndr 2009; 52 Suppl 1: S20-3

21. Ivers LC, Jerome JG, Cullen KA, Lambert W, Celletti F, Samb B. Task-shifting in HIV care: a case study of nurse-centered community-based care in Rural Haiti. PloS One 2011; 6(5): e19276.

22. Fredlund VG, Nash J. How far should they walk? Increasing antiretroviral therapy access in a rural community in northern KwaZulu-Natal, South Africa. The Journal of Infectious Diseases 2007; 196 Suppl 3: S469-73

23. Loubiere S, Boyer S, Protopopescu C, et al. Decentralization of HIV care in Cameroon: increased access to antiretroviral treatment and associated persistent barriers. Health Policy 2009; 92(2-3):165-73

24. E Hulela JP, N Ndwapi, A Ali, A Avalos, P Mwala, T Gaolathe, K Seipone. Task shifting in Botswana: empowerment of nurses in ART rollout. International AIDS Conference; Mexico City 2008

25. Namugrwere A. The role of nurses in prescribing ARVs in the ART era, what is the way forward. International AIDS Conference; Rome 2011

26. H Kamiru JV, V Okello, S Mndzebele, K Bruce, P Preko, F Louis. Increasing access to ART care and treatment through decentralization: early lessons from the Swaziland national AIDS program and ICAP experience. International AIDS Conference; Vienna 2010

27. Fairall L. The effect of task-shifting antiretroviral care in South Africa: a pragmatic cluster randomised trial. STRETCH: Streamlining Tasks and Roles to Expand Treatment and Care for HIV. 5th South African AIDS Conference; Durban2011.

28. Colvin CJ, Fairall L, Lewin S, et al. Expanding access to ART in South Africa: the role of nurseinitiated treatment. South African Medical Journal 2010; 100 (4): 210-2.

29. Philips M, Zachariah R, Venis S. Task shifting for antiretroviral treatment delivery in subSaharan Africa: not a panacea. Lancet 2008; 371 (9613): 682-4 